\title{
REPENSANDO A FORMAÇÃO DO ENFERMEIRO E INVESTINDO NA PESSOA : ALGUMAS CONTRIBUIÇÕES DA ABORDAGEM GESTÁLTICA ${ }^{1}$
}

\author{
RETHINKING NURSING TRAINING AND INVESTING IN THE PERSON: \\ CONTRIBUTIONS FROM THE GESTALT PERSPECTIVE
AL REPENSAR LA FORMACIÓN DEL ENFERMERO E INVERTIR EN LA PERSONA: ALGUNAS CONTRIBUCIONES BAJO LA PERSPECTIVA GESTÁLTICA

Elizabeth Esperidião ${ }^{2}$

Denize B. Munari ${ }^{3}$

\begin{abstract}
RESUMO: Apesar do amplo discurso da integralidade do ser humano, verificamos que a formação dos profissionais de saúde tem privilegiado a competência técnica, desconsiderando-se a necessidade de instrumentalizar o processo de crescimento interno de cada um. $O$ objetivo deste estudo é refletir sobre o desenvolvimento da pessoa, enquanto instrumento básico do próprio trabalho. Consideramos que não há como desvincular a dimensão profissional da pessoal, pois interagimos na totalidade. Assim, entendemos que a pessoa reside no Ser profissional, ou de forma dialética, que o profissional integra a pessoa humana que este é. Tais considerações, que julgamos serem fundamentais no desenvolvimento de cada um, geralmente não fazem parte do aprendizado de vida, pessoal ou profissional. Nossa intenção, nesta reflexão, é tornar esse aspecto como fundamento na formação do profissional enfermeiro, ampliando a possibilidade de integrar e transcender qualquer um dos lados, a partir da abordagem holística, que contempla o desenvolvimento da pessoa de forma integral e integrada.
\end{abstract}

PALAVRAS-CHAVE: enfermagem, ensino, gestalt

\section{INTRODUZINDO O TEMA}

"O sujeito jamais pode ser separado do objeto que observa" Rollo May

Ao apresentarmos este trabalho, pretendemos compartilhar algumas inquietações que nos acompanham, fruto do nosso amadurecimento, no exercício da docência, preparando profissionais de saúde, como pessoas que somos, em constante interação com pessoas, ouvindo-as, e acima de tudo, nos ouvindo e refletindo.

Assim, temos como objetivo neste trabalho, refletir sobre o desenvolvimento da pessoa,

\footnotetext{
${ }_{1}$ Pesquisa financiada pelo CNPq/ vinculada ao Núcleo de Estudo e Pesquisa em Saúde Integral FEN/UFG

${ }^{2}$ Enfermeira Psiquiátrica e Psicóloga. Profa Assistente da Faculdade de Enfermagem da UFG. Doutoranda em Enf. Psiquiátrica da EERP/USP

${ }^{3}$ Doutora em Enfermagem. Profa Titular da Faculdade de Enfermagem/UFG
} 
enquanto instrumento básico do próprio trabalho.

A visão holística e existencialista de homem auxilia-nos na compreensão de algumas dessas questões. Percebemos que pouca atenção se tem dado ao cuidado do homem como um todo, especialmente, no que se refere à assistência à saúde e na formação de recursos humanos para esta área, mais particularmente, ao cuidado que o profissional de saúde tem de si próprio.

Ao fazermos essa reflexão temos a intenção de sensibilizar as pessoas para o encontro consigo mesmo, movimento que consideramos de extrema relevância para ampliarmos a possibilidade de entender o que se passa comigo e com o outro, quando buscamos efetividade nas relações que estabelecemos.

Concordamos com a afirmação de Miranda (1996) indicando ser este um caminho mais saudável para quem escolheu conviver com a dor humana, sendo que, na enfermagem, essa é a realidade do cotidiano.

Apesar do amplo discurso da integralidade do ser humano, como ser bio-psico-sócioespiritual, este é visto sob fragmentos, não é compreendido enquanto ser total. Esta atitude ignora a premissa básica da teoria organísmica de Goldstein, apropriada pela abordagem gestáltica, no que diz respeito à psicologia da pessoa, que concebe o ser humano como organismo total, sendo qualitativamente diferente da soma de suas partes e que, portanto, age como um todo (Perls, 1977, Hall ; Lindzey, 1984).

A gestalt, abordagem da psicologia fundamentada na filosofia humanista, na teoria de campo, na teoria holística e na fenomenologia existencial, ampara nosso modo de pensar e trabalhar na enfermagem, guiando nossas ações no sentido de buscarmos a integração da pessoa e do profissional. O termo gestalt, derivado do alemão, não tem tradução literal para o português, mas sugere uma idéia de totalidade, de partes que se unem em um todo convergente e significativo, assumindo um sentido de unidade (Perls,1977, Ribeiro,1994).

O ser humano anseia pela totalidade e a incompletude o deixa angustiado. Ribeiro (1994) afirma que, existe em nós, uma tendência ao completo, ao perfeito, à unidade total e absoluta, o que significa olhar a realidade como um todo. O sentido de totalidade, essencial para a abordagem gestáltica, é definido como um apelo de organização do sujeito num dado campo, que implica também na idéia de relação. Enquanto seres de relação, vamos nos constituindo no existir, partindo da nossa relação intrapessoal, completando-nos através das nossas interações com o meio, pois na condição de organismo só existimos num contexto. A forma que entramos em relação é altamente significativa, fornece pistas do nosso jeito de ser-nomundo, da originalidade do nosso ser. Neste sentido, consideramos que não há como separar o nosso lado profissional do nosso lado pessoal, aspecto também apontado por Stacciarini e Esperidião (1999) e Fenilie Scóz (2000).

Interagimos na totalidade, independentemente se tivermos consciência desta realidade ou não. Ao tomarmos conta do que se passa conosco, favorecemos relações mais humanizadas na medida em que valorizamos a singularidade e a subjetividade de cada um, resgatando o valor da pessoa na relação humana.

A despeito de sabermos que as dimensões humanas não podem ser isoladas numa pessoa, fica a questão em como organizar a nossa compreensão acerca delas, na constituição da pessoa concreta, na organização das suas categorias mentais, sua ação e comportamento. Fonseca (1998) lembra que a pessoa antes de se constituir como um eu, organiza seu comportamento, a sua percepção de si e do mundo, em função dos padrões organizativos do seu agrupamento, na concretude de seu momento histórico. A organização da pessoa não se dá apenas numa determinada fase do seu desenvolvimento, mas a cada momento de sua atualidade, num processo de constituição de si. 


\section{O DESENVOLVIMENTO DA PESSOA}

Aventurar-se causa ansiedade, mas deixar de arriscar é perder a si mesmo.... Aventurar-se no sentido mais amplo é precisamente tomar consciência de si mesmo Kierkegaard

Consideramos relevante refletir acerca de como vamos constituindo a nossa existência, na medida em que compreendemos o ser humano em constante desenvolvimento, que no sentido gestáltico, é um ser de possibilidades, rumo à integração intrapessoal e interagindo com as várias partes da natureza, da qual faz parte.

Daí, nossa preocupação no desenvolvimento do profissional enfermeiro, a partir da pessoa que o habita,o sentido de buscarmos integração e articulação entre essas duas dimensões. 0 desenvolvimento de algumas habilidades pode favorecer um melhor contato e encontro de si mesmo, o que reforça a idéia de que não há limites para o aprendizado, quando se tem intenção de estabelecer relações interpessoais significativas.

Esperidião e Capel (1999) apontam que os contatos com os elementos intrapessoais estão intimamente ligados às necessidades relacionais do ser humano, portanto, sempre presentes na nossa prática profissional. Reconhecem que, através do contato, podemos refletir sobre a nossa existência individual e a do outro, pois ao fazer contato me vejo como um ser separado, sozinho no universo, mas, também, em relação com outros indivíduos (Ribeiro, 1997).

Entendemos que a pessoa, o Ser humano, reside no ser profissional e que a pessoa do profissional integra a pessoa humana, de forma dialética. Não vemos como separá-los, pois a divisão traz o perigo de se reduzir dimensões indivisíveis pela própria natureza do humano, a despeito das inúmeras divisões a que somos submetidos no cotidiano e as implicações decorrentes disso.

Consideramos fundamental a idéia de que o organismo como um sistema organizado é compreendido a partir da unidade e da integração na sua dinâmica funcional, onde um elemento nunca abstraído do todo ao qual pertence, embora seja diferenciado em suas partes (Hall e Lindzey, 1984). Além disso, acrescentamos o significado de pessoa a partir do humanismo, cuja idéia centra o homem como objeto próprio, valorizando e atribuindo-Ihe um sentido. Para Ribeiro (1999), ao se resgatar o humano, o positivo de cada um, revela-se o divino oculto em nossa humanidade, ou seja, o lado luminoso da relação ser e estar no mundo.

Martins (1995), ao analisar as vertentes que influenciam a Gestalt-terapia, no referente à concepção de homem, diz que este só pode ser entendido se o conhecermos na sua totalidade, como uma Gestalt, e não composto por partes, o que traz uma implicação básica de assumirmos uma postura holística.

Rogers (1992), através da sua teoria centrada na pessoa, acredita que todos têm dentro de si as potencialidades para a saúde e o crescimento criativo. Estas afirmações ratificam nosso pensamento, no sentido de que é preciso buscar o encontro de si mesmo e investir na integração intra e interpessoal, garantindo um desenvolvimento saudável e harmonioso.

Algumas reflexões acerca da noção de pessoa feitas por Holanda (1998), remete a uma consideração de homem como um ser vinculado à sua realidade e ao mundo, fundamentado nas filosofias de Rogers e Buber, delegando, à pessoa, poderes sobre si mesma. Hycner (1995), por sua vez, ao propor a postura dialógica na relação terapêutica, centra a cura através do encontro, incluindo as relações EU-TU e EU-ISSO, enfatizando a totalidade da pessoa envolvida.

Tais considerações são fundamentais quando nos referimos ao desenvolvimento de cada um e, geralmente, não fazem parte do nosso aprendizado de vida, pessoal ou profissional. Nos dias de hoje, quando vivemos uma era de grandes transformações tecnológicas e sócio-culturais, verificamos que muitas vezes a educação, seja ela formal ou não, coloca estes aspectos à parte e, lamentavelmente, muitas vezes, nem mesmo como fundo neste processo. Nossa intenção, aqui, é torná-los figura no sentido gestáltico, neste exato aqui-e-agora, embora 
admitindo a necessidade de resguardar a dinâmica do funcionamento figura-fundo, num determinado campo perceptivo.

\section{OBSERVANDO ALGUMAS TENDÊNCIAS NA FORMAÇÃO DO ENFERMEIRO}

A verdade está nas pessoas e não nas idéias

Husserl

Apesar de existir um movimento de transformação na concepção dos currículos de enfermagem que contemplam alguns destes aspectos de natureza filosófica e pedagógica, verificamos que ainda se privilegia a competência técnica do profissional, desconsiderando-se a necessidade de instrumentalizar o processo de crescimento interno de cada um (Brant; Antunes, 1995, Munari; Rodrigues, 1997, Stacciarini; Esperidião, 1999). Por outro lado, encontramos estudos que manifestam a necessidade do investimento na pessoa, enquanto instrumento básico do próprio trabalho, procurando (re)tomar como ponto de partida o gênero humano e suas habilidades intrapessoais, no sentido de facilitar o estabelecimento de relações mais humanizadas consigo mesmo e com os outros (Pessoti, 1996, Gonçalves, 1998, Juliano, 1998, Esperidião; Munari; Stacciarini, 1999, Andrade, 1999, Esperidião; Capel, 1999).

As indicações emanadas do $4^{\circ}$ Seminário Nacional de Diretrizes para o Ensino de Enfermagem (SENADEn, 2000), ocorrido em Fortaleza, sugerem que pensemos a formação do enfermeiro dentro da perspectiva do seu desenvolvimento técnico, ético e humanista. Sem dúvida alguma, a formação da pessoa encontra-se explicitamente em pauta, embora não seja tão simples darmos conta da dimensão ética e humanista, o que contempla exatamente a essência de nossos questionamentos.

Ao vivenciarmos um momento de intensas resignificações éticas, morais, religiosas e culturais, que influenciam os valores de cada pessoa, vimos a necessidade em reestruturarmos nossa postura com o aluno de enfermagem. O trabalho de Romano,Papa e Lopes (1997) apresenta-nos algumas possibilidades para vivenciarmos a formação do enfermeiro através de uma posição que exige a adoção de uma nova relação docente-discente. Para as autoras, "este processo requer uma relação dialógica na relação professor aluno, onde ambos caminham juntos na busca da leitura do mundo, da compreensão do contexto" (p.414).

A situação atual é importante na medida em que as instituições vivenciam o processo de repensar e reestruturar o ensino e é nesse contexto que acreditamos ser o momento propício para abrir espaço à questão de se cuidar da pessoa que se tornará um profissional.

Analisamos tais tendências como um movimento de resgate e valorização de aspectos relativos à existência humana, em busca de sua essência, enquanto Ser, além de sinalizar que estamos diante de outros referenciais, frutos de num novo tempo. Tractenberg (1999) afirma que o pensar e agir das pessoas estão sendo influenciados e influenciam na elaboração de novos paradigmas, no campo das relações intra e interpessoais, da visão sobre a natureza, constituindo-se numa nova abordagem mais humanizada, sistêmica e integradora.

\section{APRESENTANDO UMA POSIÇÃO}

É verdade, para todo indivíduo, que ele pode, à qualquer momento escolher tornar-se ele mesmo, que é a única maneira de viver uma vida autêntica

Clark Moustakas

Ao nos aproximarmos dessas questões, sobre o aprofundamento do como preparar profissionais, de modo pleno e consciente, desde que contemple o desenvolvimento da pessoa 
de forma integral e integrada, verificamos que, de fato, o processo de formação acadêmica não tem incluído aspectos que possibilitem o fortalecimento emocional dos profissionais de saúde, num movimento nítido de desconsideração dos agravos que as situações ansiogênicas a que são continuamente submetidos podem oferecer.

Machado, Caldas e Bertoncello (1997) alertam que o ensino das profissões de saúde deverá passar por profundas mudanças nas próximas décadas, pois se evidencia sinais de esgotamento, exigindo a construção de novos modelos de formação e capacitação de recursos humanos em saúde.

O movimento de globalização, amplamente discutido nos dias de hoje, nos impõe, segundo Santomé (1998), a necessidade de repensar as relações do homem no mundo. Mais que isto, percebemos a necessidade dos profissionais repensarem a compreensão de si mesmos, de forma a garantir suas próprias necessidades, revendo sua visão de mundo, de homem, do modo de assistir o ser humano e de lidar com a saúde e com a doença. Assim, acreditamos que um dos caminhos possíveis inicia-se com o autoconhecimento, ou seja, experienciar a si mesmo, para aproximar-me da experiência do outro.

Fernandes, Mota, Oliveira et al. (2000) apresentam em suas conclusões alguns indicativos para se incrementar as relações interpessoais no contexto das organizações, sendo, um deles, oferecer espaço ao enfermeiro para que ele possa "abrir canais para ampliar idéias acerca de si mesmo, de outros e da própria organização de maneira integrada" (p.74), sinalizando ser este um grande desafio.

Concordamos com as autoras e acreditamos que esse não é apenas um desafio para os gerentes. Ele deve, na verdade, ser um exercício de repensar o ensino de enfermagem desde a graduação do enfermeiro e um instrumento na busca da sua competência interpessoal e satisfação profissional.

Este repensar possivelmente influenciará as atitudes frente ao indivíduo que atendemos, na medida em que fundamentamos o encontro não mais no modelo biomédico, mas na dimensão bio-psico-social que valoriza o cuidado à pessoa. Ao abrirmos possibilidades para que tais questões sejam discutidas e experienciadas durante a formação, dentro ou fora da academia, estaremos nos capacitando e nos tornando mais comprometidos com o atendimento dispensado às pessoas.

Ao reconhecermos o futuro profissional como pessoa, possibilitamos a ele oportunidade para o reconhecimento de si mesmo, como instrumento básico no cuidado, no sentido de facilitar o encontro com o outro, de forma mais humanizada, ou seja, de pessoa a pessoa. Leoni (1996, p.50) destaca que "a eficiência do profissional depende diretamente de suas atitudes para consigo mesmo e para como os outros. A vida e as pessoas é que nos dão materiais experienciais para que adquiramos os conhecimentos que nos levam a atitudes".

Pensamos que é fundamental assumirmos uma posição diante dos desafios postos ao ser humano para o enfrentamento de uma nova era, cujas tendências exigem do profissional do futuro o perfil de uma pessoa capaz de investir no seu autoconhecimento, com vistas a uma visão autêntica de si mesmo, que seja ágil e criativo na resolução de problemas, que tenha conhecimento variado e eclético e com habilidades nas relações humanas.

A literatura mostra que a orientação do homem para uma nova ordem é no sentido da busca da excelência do ser humano como pessoa, considerando a educação como um processo de integração do corpo, dos sentimentos, da mente e do espírito, completa e equilibrada, que oferece ao mundo pessoas informadas a seu respeito e também dirigidas a ela (Naranjo, 1991, Burnier, 1991, Ribeiro, 1991, Weil, 1993, Greiner, Valiga,1998).

Assim como Rodrigues, Scatena, Giacon et al. (1997), entendemos que para chegarmos a uma atitude profissional de pessoa a pessoa, precisamos nos conhecer, o que implica, buscar dentro de nós a fonte do amor e o sentido que atribuímos a cada situação vivida. Desta forma, passamos a ter mais consciência e melhor discernimento a respeito de nossas atitudes e a 
nos enxergar como pessoas.

Moretto, Mansur e Júnior et al. (1998) afirmam que o objetivo último do processo educacional do homem é o desenvolvimento global, harmônico, holístico, de sua pessoa como unidade cognitiva e emocional.

A competência interpessoal, termo usado por Moscovicl (1985; 1997) e Goleman (1996) e aqui trazido no sentido de instrumentalização emocional do sujeito, só é desenvolvida se ele estiver disposto, pelo menos, a considerar o autoconhecimento como peça fundamental na sua formação profissional. "Se, concretamente, queremos aproximarmo-nos da ajuda a outros, cabenos olhar, profundamente, dentro de nós mesmos, e olhar cada ser, para compreender as razões do comportamento humano; ver e sentir melhor a si mesmo e aos outros contatos, e expressar sentimentos em relação a própria pessoa e as que a cercam" (Leoni, 1996, p. 54).

Durante o processo ensino-aprendizagem, quando possibilitamos ao aluno perceber-se enquanto pessoa e mostrar-se não somente como profissional, sua participação é intensificada, valorizada e as avaliações destas experiências reveladas como contribuições significativas, no tocante à necessidade de auto realização e crescimento pessoal (Saeki;Munari; Alencastre et al. 1999, Moretto;Munari;Júnior, 1998, Stacciarinl; Esperidião, 1999, Fenili; Scóz, 2000).

\section{ANALISANDO ESTE CONTEXTO}

Existe, pois, uma condição para que a compreensão do outro seja possível: é que eu não seja para mim mesmo uma pura transparência

J.F. Lyotard

Vários estudos apontam dificuldades a serem transpostas quando trabalhamos questões pessoais na preparação de profissionais, mostrando que esse movimento é carregado de resistências internas, medo de lidar com as emoções e sentimentos, sendo geralmente deixados de lado, em função do atendimento dos aspectos técnicos (Filizola ;Ferreira, 1997, Rodrigues;Scatena; Giacon et al., 1997, Santos, 1997)

Acreditamos que, como participantes ativos na formação de profissionais, temos muito a contribuir nesse processo, uma vez que pela própria natureza do nosso trabalho, estamos continuamente fazendo contato com as partes do comportamento das pessoas, com vistas à sua totalidade. Ao estarmos no encontro com o outro, a partir de nós mesmos, ampliamos a possibilidade de integrar o profissional ao pessoal, transcendendo qualquer um dos lados em separado e caracterizando, de fato, uma postura dialógica, com fundamentação holística.

Consideramos, entretanto que, experienciar articuladamente as cinco dimensões da existência humana (afetiva, racional, social, física e espiritual) tem a ver com arte, pois elas são partes que se manifestam num dado momento e campo, a depender do contato que fazemos com nossas necessidades. Arte, no sentido da integração harmoniosa almejada por toda pessoa, tornando-se uma questão de saúde plena.

As dificuldades do ser humano em contatar suas intimidades, sentimentos e desejos, são reais, razão pela qual lidar com questões mais concretas, objetivas e técnicas na vida profissional pode oferecer um campo mais seguro ao enfermeiro. Rodríguez, Scatena, Giacon et al. (1997), Filizola e Ferreira (1997) e Santos (1997) discutem os obstáculos em se lidar com as resistências internas, o que acaba por privilegiar o maior desenvolvimento de aspectos técnicos.

O processo de amadurecimento expresso por nossas idéias aqui apresentadas, contém nosso envolvimento e investimento pessoal, sempre na tentativa de integração, a partir do momento que nos colocamos disponiveis para revermos nossa postura, atitudes, sentimentos e valores, que favoreceram o contato da pessoa que existe dentro da profissional.

Neste sentido, destacamos a importância da abordagem gestáltica neste caminhar, 
sinalizando momentos de necessidade em separar as partes do todo, para experienciá-las, assim como um movimento em integrá-las, na busca de um encontro intrapessoal mais autêntico.

ABSTRACT: Despite the widespread emphasis on human wholeness, the training of health professionals has privileged technical competence, desconsidering the need to strengthen the person's process of inner growth. The purpose of this article is to reflect on the importance of a person's development as a basic tool of one's own work. The authors consider that there is no way to separate the personal from the professional dimension since each person interacts as a totality. Thus, the person exists in the professional Being or, dialectically speaking, the professional integrates the human being that it really is. These considerations, which are fundamental to each one's development, usually are not part of one's life, personal or professional learning. It is necessary to make this an essential part of nursing training, broadening the possibilities of integrating and transcending either side of the person, by introducing an holistic approach which contemplates the human being development in an integral and integrated way.

KEYWORDS: nursing, teaching, gestalt

RESUMEN: A pesar del amplio discurso de la integridad del ser humano verificamos que la formación de los profesionales de la salud ha estado priorizando la competencia técnica y se ha desconsiderado la necesidad de instrumentalizar el proceso de crecimiento de nuestro interior. El objetivo de este estudio es reflexionar sobre el desarrollo de la persona, mientras instrumento básico del propio trabajo. Consideramos que no hay como desvincular la dimensión profesional de la personal, pues interactuamos dentro de una totalidad. Así, entendemos que la persona reside en el Ser profesional - -de forma dialéctica- que el profesional integra la persona humana que este es. Tales consideraciones, que juzgamos fundamentales en el desarrollo de cada uno, generalmente no forman parte del aprendizaje de vida, personal o profesional. Nuestra intención, en esta reflexión, es hacer que ese aspecto se vea como fundamento en la formación del profesional enfermero, de ahí, ampliando la posibilidad de integrar y trascender cualquiera de los lados, a partir de la perspectiva holistica, que contempla el desarrollo de la persona de forma integral e integrada

PALABRAS CLAVE: enfermería, enseñanza, gestalt

\section{REFERÊNCIAS BIBLIOGRÁFICAS}

ANDRADE, C. C. A visão gestáltica na relação médico-paciente. Rev. V Encontro Goiano da abordagem gestáltica, Goiânia, n.5, p. 35-40, maio 1999.

BRANT, M.J.C.G.C; ANTUNES, M.J.M. Concepções pedagógicas: influência na educação e na prática de enfermagem. In: CONGRESSO BRASILEIRO DE ENFERMAGEM, 47: Goiânia, 1995. Sínteses.. Goiânia: Centro Editorial e Gráfico UFG,1995. p.169-170

BURNIER, R. Em direção a uma ordem mundial. In. BRANDÃO, D.M.S. \& CREMA, R. O novo paradigma holístico: ciência, filosófica, arte e mística. São Paulo: Summus, 1991

ESPERIDIÃO, E.; CAPEL, J. Contatando o ser psicólogo através da sucata. Rev. V Encontro Goiano da abordagem gestáltica, Goiânia, n.5, p.107-110, maio 1999.

ESPERIDIÃO, E.; MUNARI, D. B.; STACCIARINI, J.M.R. Desenvolvendo pessoas: a importância do autoconhecimento para a formação do enfermeiro. In: CONGRESSO BRASILEIRO DE ENFERMAGEM, 51., Florianópolis, 1999. Mimeografado. 
FENILI, R. M.; SCÓZ, T. M. X. Sentimentos dos alunos no início e término de uma relação pessoa a pessoa estabelecida com cliente psiquiátrico. Nursing, São Paulo, n. 23, p.16-19, abril 2000.

FERNANDES, J.D. ; MOTA, G.L.C. ; OLIVEIRA, M.R. e LUCENA, R. Relações interpessoais no contexto organizacional: representações sociais de profissionais de saúde. Rev. RENÉ. v.1, n.1, p.68-75, jan./jul.2000.

FILIZOLA, C.L.A.; FERREIRA, N.M.L.A. O envolvimento emocional da equipe de enfermagem: realidade ou mito? Rev. Lat. Americ. Enfermagem, Ribeirão Preto, v.5, p. 09-18, maio 1997. Número especial.

FONSECA, A.H.L. Transindividualidade, individualidade, pessoa e psicologia. on line]. p.1-10. 1998. p. disponivel em <http:// www.terravista.pt/FerNoronha/1411. > [acesso em 2000, abril - 3].

GOLEMAN, D. Inteligência emocional. Rio de Janeiro: Objetiva, 1996.

GONÇALVES, E. L. Os objetivos da educação médica. Rev. Bras. Educ. Méd., Rio de Janeiro, v.22, n 2/3, p.9-18, set./dez. 1998.

GREINER, P.A.; VALIGA, T.M. Creative educacional strategies for health promotion. Holist. Nurs. Pratic. v. 12, n. 2, p. 73-83, 1998.

HALL, C. S; LINDZEY, G. Teorias da personalidade. 18. ed. São Paulo: EPU, 1984. v. 2, cap. II, p. 2955: Teoria organísmica.

HOLANDA, A.F. Diálogo e psicoterapia: correlações entre Carl Rogers e Martin Buber. São Paulo: Lemos Editorial, 1998.

HYCNER, R. De pessoa a pessoa: psicoterapia dialógica. São Paulo: Summus, 1995.

JULIANO, J.C. Ser terapeuta. Rev. IV Encontro Goiano da abordagem gestáltica, Goiânia, n.4, p.1-4, maio 1998.

LEONI, M.G. Auto-conhecimento do enfermeiro da relação terapêutica. Rio de Janeiro: Cultura Médica, 1996

MACHADO, J.L.M.; CALDAS, A ; BERTONCELLO, N.M.F. Uma nova iniciativa na formação dos profissionais de saúde. Interface: comunicação, saúde, educação. Botucatu, v.1. n.1, p. 147-56, ago. 1997

MARTINS, A.E.O. A concepção de homem em gestalt-terapia e sua implicação no processo psicoterápico. Rev. I Encontro Goiano de Gestalt-terapia, Goiânia, n.1, p. 47-71, mar./abr. 1995.

MIRANDA, C. F. Atendendo o paciente: perguntas e respostas para o profissional de saúde. Belo Horizonte: Crescer, 1996

MORETTO, R.A; MANSUR, O.F.C; JUNIOR, J.A. Humanismo e tecnicismo na formação médica. Rev. Bras. Educ. Méd., Rio de Janeiro, v.22, n.4, p. 19-25, jan./abr. 1998.

MOSCOVICI, F. Desenvolvimento interpessoal. Rio de Janeiro: Livros Técnicos, 1985

1997. Razão e Emoção: a inteligência emocional em questão. Salvador: Casa da Qualidade,

MUNARI, D.B; RODRIGUES, A.R.F. Enfermagem e Grupos. Goiânia: AB, 1997 
NARANJO, C. Educando a pessoa como um todo para um mundo como um todo. In: BRANDÃO, D.M.S. e CREMA, R. Visão holística em psicologia e educação. São Paulo: Summus, 1991

PERLS, F. S. Isto é Gestalt. São Paulo: Summus, 1977.

PESSOTI, I. A formação humanística do médico. Medicina, Ribeirão Preto, n.29. p.440-448, out./dez. 1996.

RIBEIRO, J.P. Educação holística. In BRANDÃO, D.M.S. e CREMA, R. Visão holística em psicologia e educação. São Paulo: Summus, 1991.

Gestalt-terapia: o processo grupal - uma abordagem fenomenológica da teoria de campo e holística. São Paulo: Summus, 1994

1997. O ciclo do contato: temas básicos na abordagem gestáltica. 2. ed. Petrópolis: Summus,

A visão de pessoa humana na abordagem gestáltica. Rev . V Encontro Goiano da abordagem gestáltica, Goiânia, n.5, p. 11-22, maio 1999.

RODRIGUES, A.R.F.; SCATENA, M.C.M.; GIACON, A. V.; SANTANA, J.A. Opinião de enfermeiros a respeito de suas interações com os pacientes. In: CONGRESSO DE SAÚDE MENTAL DO ESTADO DO RIO DE JANEIRO, I., 1997. Anais... Rio de Janeiro. p. 455-715

ROGERS, C. R. Terapia centrada no cliente. São Paulo: Martins Fontes, 1992

ROMANO, R. A T; PAPA, L.M.P. e LOPES, G.T. Construção de um currículo integrado de enfermagem. Rev. Bras. Enferm. v.50, n.3, p.407-424, jul./set. 1997.

SAEKI, T; MUNARI, D. B; ALENCASTRE, M. B; SOUZA, M. C. B. Reflexão sobre ensino de dinâmica de grupo para alunos de graduação em enfermagem. Rev. EEUSP. v. 33, n.4, p.342-47, Dez 1999.

SANTOMÉ, J.T. Globalização e interdisciplinariedade: o currículo integrado. Porto Alegre: Artes Médicas, 1998.

SANTOS, M.L. O trabalho dos "Anjos de Branco": um estudo em um hospital geral público. In: CONGRESSO DE SAÚDE MENTAL DO ESTADO DO RIO DE JANEIRO, I., Rio de Janeiro, 1997. Anais... Rio de Janeiro. p. 496-509.

SENADEn - SEMINÁRIO NACIONAL DE DIRETIZES PARA O ENSINO DE ENFERMAGEM. 4; Fortaleza, 2000. Relatório Final... Brasília: Associação Brasileira de Enfermagem, 2000

STACCIARINI, J.M.R.; ESPERIDIÃO, E. Repensando estratégias de ensino no processo de aprendizagem. Rev. Lat.-Americ. Enfermagem, Ribeirão Preto, v. 7, n. 5, p.59-66, dez. 1999.

TRACTENBERG, L. A complexidade nas organizações: futuros desafios para o psicólogo frente à reestruturação competitiva. Psicologia - Ciência e Profissão, Brasilia, n. 1, p. 14-29; 1999.

WEIL, P. Organizações e Tecnologias para o terceiro Milênio: a nova cultura organizacional Holística. Rio de Janeiro: Rosa dos Tempos, 1993.

Recebido em agosto de 2000 Aprovado em novembro de 2000 